\title{
Zhuhai exhibition activities volunteers Investigation and Research on
}

\section{service status}

\author{
YuMei Han"1, a, Ting Yuan², \\ 1,2School of Tourism Management, Zhuhai City Polytechnic, Zhuhai,519000 China; \\ a2373540696@qq.com, b54132577@qq.com
}

Keywords-volunteer, activity, college student.

\begin{abstract}
The Zhuhai student volunteers participate in the exhibition of volunteer activities, to learn their attitude, volunteer training, volunteer allocation and coordination, incentive, security and other aspects, summarize the successful experience and put forward suggestions for improvement according to the survey data, the Zhuhai Convention and exhibition activities aimed at improving students volunteer service level.
\end{abstract}

I. Zhuhai exhibition activities college students volunteer service status survey results and analysis

subjective awareness of volunteer activities by College Students. 1)college student volunteers' understanding of participating in voluntary activities. Through the questionnaire feedback, found that $83 \%$ of Undergraduates of the volunteers that participate in volunteer service activities is a very meaningful social activities, $71 \%$ of people think that volunteering helps to cultivate the consciousness of team cooperation and understanding to help others, $51 \%$ of people think that participating in volunteer activities can have the opportunity to use professional skills, enhance myself, $75 \%$ of people think that helps to broaden our horizons, increase their knowledge, $49 \%$ of people think that can help to enhance their sense of social responsibility, but $15 \%$ of people think it is a waste of time, no meaning. See Table 1. More than half of the students have a positive attitude towards the awareness of voluntary activities.

2)The enthusiasm of College Students' volunteers to participate in the volunteer activities. The survey found that the students' enthusiasm of volunteers to participate in activities worthy of consideration, according to the survey results, the survey of $4.94 \%$ people to volunteer more disgusted, $12.35 \%$ of people think that do not do nothing, $12.35 \%$ of the students will actively pay attention to volunteer information, $39.51 \%$ student volunteers to participate in voluntary activities in order to earn credits and service hours, $30.86 \%$ volunteers will have the opportunity to participate in volunteer activities.

Now many universities have the volunteer service as one of the standard of students' quality assessment, provides many opportunities for students to participate in volunteer service activities, but did not consider the students' time and energy is limited, in the busy to complete their schooling, and some volunteer activities and students class time conflict, also led to participate in volunteer activities can not achieve the desired purpose.

3) university volunteers' working attitude towards volunteers 
According to the results of the survey, to occasionally active, $25.5 \%$ of the students in the volunteer service period is in a passive work. See Table 2. For the problems and their lack of presence in the volunteer service work, there are $15.3 \%$ student volunteers carefully own

Table 1 The enthusiasm of working tasks during voluntary service

\begin{tabular}{llll}
\hline attitude & number & $\%$ & sort \\
\hline Very active & 28 & 15.1 & 4 \\
More active & 48 & 26.3 & 2 \\
Occasional initiative & 563 & 34.1 & 1 \\
Never take the initiative & 47 & 25. & 3 \\
\hline
\end{tabular}

communication at work there are some problems, $7.8 \%$ of people admit that they are absent or late, $34.3 \%$ student volunteers that their processing ability for the incident problems, $21.2 \%$ of the students think that their volunteer work state not good enough, 30.3\% volunteer students think of themselves in the exhibition theme of their knowledge of the lack of understanding.

These data indicate that most college students volunteer or volunteer work seriously, after all, the service is a large group activity, when faced with an emergency lack of social experience, I do not know how to face, feel at a loss what to do, will affect the enthusiasm of their work.

4) college student volunteers' sense of responsibility. The survey found that $23 \%$ of students in the volunteer people think that being a

Table 2the sense of responsibility of College Students' Volunteers

\begin{tabular}{lllc}
\hline option & number & $\%$ & sort \\
\hline As a volunteer, we should be brave and responsible. & 43 & 23 & 3 \\
In the case of unfinished work, the responsibility is not & 58 & 31 & 1 \\
entirely on its own & & & \\
Not taking the initiative to work will affect your image & 23 & 17 & 4 \\
There is no idea of shirking responsibility.but lack of & 54 & 29 & 2 \\
courage to take responsibility & & & \\
\hline
\end{tabular}

volunteer should take the initiative to take responsibility, not to complete the work, $31 \%$ of people think the responsibility is not fully, there are $17 \%$ the work will affect their leaders and students in image. $29 \%$ of the students think that they do not have the idea of shirking their responsibilities, but they lack the courage to take responsibility. See Table 2.

In the process of college volunteers' participation in volunteer service, $63.2 \%$ of them had problems, and they could communicate with relevant leaders in time, and 36.8\% of them couldn't contact leaders in time to communicate. It shows that the communication ability of college students themselves needs to be improved.

The survey found that college student volunteers in volunteer service work, $13.7 \%$ of the students can always put forward proposals or improved methods, $22.3 \%$ of the students sometimes put forward the suggestion and towards work suggestions and methods of improvement are also required. $35.1 \%$ of the students occasionally put forward proposals or improved methods, $28.9 \%$ student volunteers never propose the suggestion and method. See Table 3, indicating that college students' working attitudes.

According to the survey results, college students can see volunteers participating in the exhibition activities during the service, if you have never met or leadership. 
Table 3 whether to propose a work proposal or a method of improvement

\begin{tabular}{lllc}
\hline option & number & $\%$ & sort \\
\hline Always put forward & 25 & 13.7 & 4 \\
Sometimes put forward & 41 & 22.3 & 3 \\
Occasionally put forward & 66 & 35.1 & 1 \\
Never put forward & 54 & 28.9 & 2 \\
\hline
\end{tabular}

Table 4 If a leader has missed or met a problem that has never occurred.

\begin{tabular}{lllc}
\hline option & number & $\%$ & sort \\
$\begin{array}{l}\text { Solving problems with existing experience } \\
\text { independent learning }\end{array}$ & 36 & 22.6 & 3 \\
$\quad \begin{array}{l}\text { Collective discussion and joint } \\
\text { settlement }\end{array}$ & 91 & 48.7 & 1 \\
$\begin{array}{l}\text { Developing and innovating to solve the related } \\
\text { problems }\end{array}$ & 24 & 13.1 & 4 \\
$\quad$ Be careless with their free development & 29 & 15.6 & 2 \\
\hline
\end{tabular}

oversight issues, $22.6 \%$ volunteers will be combined with the existing experience of autonomous learning, to pioneering and innovative solutions the problem, but there are still $15.6 \%$ of the students will be careless with their free development, see table 4 .

\section{Countermeasures and suggestions}

Perfect the selection mechanism and improve the enthusiasm for participation. How to solve this problem, university organizations should play power, give full play to the advantages of the school community to recruit volunteers, do the propaganda work, the ideal way is to communicate according to the relevant departments of the students and teachers with the nature of exhibition activities and related professional school, which does not affect the normal school students also use of volunteer activities to meet students need to practice[2].In the process of volunteering, students think this is an effective way to improve their professional skills, and will improve the enthusiasm of the volunteer service. Of course, before entering the exhibition site, students can truly understand the meaning of volunteering, do a full range of training, do not let college volunteers feel like volunteering, thereby affecting the enthusiasm of volunteering.

Improve the training content and improve the training effect. In the way of training, it is best to take small classes. After all, the training effect of thousands of people will not achieve the purpose of training. A large number of colleges and universities have a large number of volunteers to consider the training of separate small classes, colleges and universities themselves to organize training, teachers and colleges and universities can also meet their own.

To improve the professionalization of volunteers, volunteer management organizations should understand their knowledge, skills and skills based on job analysis and job evaluation, and conduct targeted training for their members. 
Perfect the evaluation mechanism and give full play to the social benefit. First of all, volunteer service standards should be established. Universities should have specialized agencies for volunteer training. In the process of volunteer service, volunteers lack supervision, service attitude and enthusiasm need to be improved. We should establish a sound volunteer evaluation mechanism, first of all, establish a sound evaluation system. The volunteers from the social, University and organizational groups should have a supervisory mechanism, which is also a fair treatment of volunteers. The evaluation of volunteers can include the quality of service, the number of times of service, the assessment of the school skills and the ability of organization. Objective evaluation of volunteer service, so as to stimulate the participation of volunteers, improve the quality of voluntary service and improve the reputation of the school. Thus, the social benefits, social recognition, and the promotion of the virtuous circle of voluntary service work.

\section{References}

[1] Tan Jianguang. Analysis of the construction of voluntary service system in China. Research on volunteer service in China [M]. Beijing: Peking University press, 2007.

[2] Kang Xiaoguang. Nonprofit organization management [M]. Beijing: Renmin University of China press, 2009.

[3] The first national industry standard in the field of volunteer service information construction in China -- Interpretation of the basic specification of volunteer service information system, [J]., China Civil Affairs, 2015 (18).

[4] Wei Na, Wang Zhe. Volunteer service to the public service value and the effect of [J]. (1) Changbai journal, 201. 